\title{
Geraldine F. Montgomery, Noces pour lemme seule. Le féminin et le sacré dans l'rœuvre d'Albert Camus
}

\section{Emanuele Kanceff}

\section{(2) OpenEdition}

1 Journals

\section{Edizione digitale}

URL: https://journals.openedition.org/studifrancesi/38298

DOI: 10.4000/studifrancesi.38298

ISSN: 2421-5856

\section{Editore}

Rosenberg \& Sellier

\section{Edizione cartacea}

Data di pubblicazione: 15 décembre 2004

Paginazione: 649

ISSN: 0039-2944

\section{Notizia bibliografica digitale}

Emanuele Kanceff, «Geraldine F. Montgomery, Noces pour lemme seule. Le féminin et le sacré dans I'roeuvre d'Albert Camus", Studi Francesi [Online], 144 (XLVIII | III) | 2004, online dal 30 novembre 2015, consultato il 08 mai 2021. URL: http://journals.openedition.org/studifrancesi/38298 ; DOI: https:// doi.org/10.4000/studifrancesi.38298

Questo documento è stato generato automaticamente il 8 mai 2021.

\section{(c)}

Studi Francesi è distribuita con Licenza Creative Commons Attribuzione - Non commerciale - Non opere derivate 4.0 Internazionale. 


\title{
Geraldine F. Montgomery, Noces pour lemme seule. Le féminin et le sacré dans l'rœuvre d'Albert Camus
}

\author{
Emanuele Kanceff
}

\section{NOTIZIA}

GERALDINE F. MONTGOMERY, Noces pour lemme seule. Le féminin et le sacré dans l'rouvre d'Albert Camus, Amsterdam-New York, Rodopi, 2004 (Collection «Faux Titre», 242), pp. 400.

1 Quale rapporto esiste tra il femminile e il sacro? La risposta dell'A. a tale interrogativo è in sintesi la giustificazione di questo nuovo libro su Camus: «Nous voulons réagir d'abord à cette ... question. Elle touche au cœur de notre projet dont le but est précisément d'y répondre à travers l'étude de ces deux paradoxes de l'œuvre, étude qui s'attardera surtout aux moments de leur intersection, car il s'agit de l'analyse d'une relation. Alors que, dans son jeu d'absence/présence, chaque paradoxe mérite - et recevra - examen indépendamment de l'autre, ils se rejoignent à plusieurs reprises et ce de manière paroxystique dans un des derniers textes de l'auteur, La Femme adultère. Dans cette nouvelle, une femme, découvrant l'infini de son désir et «franchissant le gouffre qui sépare le désir de la conquête» est révélée à elle-même dans l'expérience du sacré. C'est pourquoi ce texte sera le point focal d'une recherche qui se fraiera un chemin préalable à travers une grande partie de l'œuvre pour y repérer les traces du sacré d'une part, celles du féminin de l'autre, et pour y cerner leurs moments de rencontre ou de fusion, dans l'espoir de mieux comprendre la complexité de cette alliance paradoxale et inattendue dans une œuvre agnostique et si souvent perçue comme masculine».

2 Noces pour lemme seule studia per la prima volta l'importante presenza femminile nell'insieme dei testi di finzione, riconducendola a quella del sacro. La presenza di questi due paradossi dell'opera traccia delle nuove linee di forza nella ricerca e mette in 
evidenza, attraverso le presenze e le voci femminili, quelle aspirazioni fondamentali rimaste spesso sconosciute.

3 L'analisi del paradosso del sacro, di ordine religioso e filosofico, cerca di conciliare l'agnosticismo dell'autore e la sua filosofia dell'assurdo, che nega tutta la trascendenza, con un senso del sacro quasi onnipresente. L'analisi del paradosso del femminile, di ordine mitico e psichico, che si manifesta attraverso un gioco alternante assenze e presenze con i silenzi e le parole, si basa principalmente su un approccio semiotico kristeviano del materno e del femminile come "ultimo rifugio del sacro".

4 Questo doppio approccio spiega le differenze metafisiche tra il maschile e il femminile, la solitudine della donna, e l'esperienza iniziatica de La femme adultère, racconto che culmina nella fusione dei due paradossi trattati - le "nozze" del femminile e del sacro.

5 Infine, è apparso chiaramente, nel corso dello studio, che la relazione del femminile e del sacro nell'opera è fondata sull'esperienza del desiderio che genera l'assenza/ silenzio dell'Altro.

6 La relazione con il sacro si realizza nell'opera su due livelli: cosmico e umano. A livello cosmico, si tratta sicuramente della relazione dell'uomo come si è potuto osservare in maniera precisa nei saggi di Noces oppure ne L'État de siège, per esempio, ma anche ne $L a$ Mort heureuse e ne L'Étranger, soprattutto nell'ultima scena di quest'ultimo, dove, confrontandosi con l'imminenza della morte, il personaggio scopre in extremis la gioia di comunicare con il mondo.

7 Si deve notare che è essenzialmente attraverso i personaggi femminili che si scopre l'espressione del desiderio spirituale, sia il desiderio assoluto del "regno di questo mondo" retto dall'Eros umano e che è quello delle donne compagne, oppure, ad un livello più profondo e più vasto, il desiderio dell"'Ame du royaume" plotiniano che è desiderio del divino e "nostalgia di una patria perduta".

Una folta bibliografia e un indice dei nomi completano il ponderoso saggio. 